\title{
Efficacy of different insole designs on fall prevention of the elderly
}

\author{
$\underline{\text { Yen-Ting Liu }}^{1,2}$, Sai-Wei Yang ${ }^{1 *}$, Keh-Tao Liu ${ }^{3}$ \\ ${ }^{1}$ Department of Biomedical Engineering, National Yang Ming University, Taipei, Taiwan \\ ${ }^{2}$ Taipei Medical University-Wan Fang Hospital, Taipei Medical University, Taipei, Taiwan \\ ${ }^{3}$ FootDisc Inc, Taipei, Taiwan \\ *Corresponding author (swyang@ym.edu.tw)
}

\begin{abstract}
Purpose Between 28 to $35 \%$ of people aged over 65 fall in a year; for those aged over 70 the falling rate is as high as 32 to $42 \%$. Many factors may lead to a fall, and these risk factors can be categorized as either endogenous or exogenous. Propriocepton biofeedback and ankle strategy are one of the basic control mechanism to keep posture balance and prevent falling. The purpose of this study was to evaluate different hardness and arch support designs in controlling the posture stability. Method A group of fifteen 'fallers', i.e fall-experienced elderly, (average age $67.7 \pm 2.4$ years) and eighteen non-faller elderly (average age $68.7 \pm 3.1$ years) were recruited for this study. The elderly were subjected to an exhaustive examination which included collecting demographic data, a proprioceptive test, a functional balance test, a Berg-balance test, as well as a dynamic balance assessment system tested with the eye open or closed (Biodex Medical System, Inc., USA) with a pressure mat (Xsensor X3, Canada) on top of the platform. Four types of orthotic insoles (Performace, Proactive, and Hardboot from Footdisc $\AA$, and Power step from Dr. Kong). The insoles each had different arch support hardness used to support ankle stability during ankle rocker motion, and cushions at metatarsal heel regions used to protect sensitive foot structure against strain and proprioception. During each test, foot pressure and the center of pressure (CoP) were recorded and analyzed. Statistical analysis was performance using SPSS v17.0 software. Results \& Discussion The faller group showed significant larger CoP excursion particularly in the medial-lateral direction, as well as the anterior-posterior mean CoP velocity with the eye opened. In the test with eye closed, the CoP trajectory increased profoundly, although the faller group was larger than the non-fallers, but this was not significant. The increased of media-lateral (ML) sway implies an increased fall risk; poor vision elevated the falling rate. With orthotics, the sway trajectory reduced, among that the Proactive insole (arch height $1.75 \mathrm{~cm}$ ) showed the best posture stability control. It reduced the ML-excursion with an average of $29 \%$ for non-fallers and $35 \%$ for fallers, respectively.
\end{abstract}

Keywords: fall risk, orthotics, posture control

\section{INTRODUCTION}

Falls are the most common and lethal accident that occur in the elderly. There are approximately $28-35 \%$ of people aged 65 and over fall each year; with age increased to 70 , the falling rate reaches to $32-42 \%{ }^{1}$. However, older community-dwelling women experience significantly more falls than do older men $^{2}$. Many factors result in falling; these risks can be categorized either endogenous or exogenous. Falls are leading causes of traumatic accidents and reducing physical activities for the elderly ${ }^{3}$. Aging is associated with changes in function of sensory and musculoskeketal system which contributes to postural stability. Postural stability has been defined as the control of the body's position in space for the purposes of balance and orientation. However, poor balance, or postural stability, is significant predictors the risk of fall in the elderly ${ }^{4}$. Postural movement patterns include three discrete control strategies: hip, knee, and ankle strategy ${ }^{5}$. The ankle rocker is an important factor to maintain balance during standing and the ankle strategy restores the center of mass (CoM) to a position of stability through body move- ment ${ }^{4}$. Propriocepton biofeedback and ankle strategy are one of basic control mechanism to keep posture balance and prevent from falling ${ }^{6,7}$. According to the age-related change, the elderly who are loss of ankle joint flexibility ${ }^{8}$ and reduce the proprioceptive acuity at the foot may be associated with functional impairment, predisposing older adults to falls ${ }^{1}$.Foot and ankle conditions in older adults are associated with mobility and balance impairment, disability, falls, and fracture $^{9}$. The planter aponeurosis plays a fundamental role in foot biomechanical mechanism during standing. As the foot transmitted the load of body weight, its longitudinal arches become length and flatten. Otherwise, the interaction of the plantar aponeurosis with skeleton of the foot is a major component of arch stability in the foot ${ }^{10}$. Foot orthoses with arch support are generally believed to align the skeleton and to maintain it curved posture to decrease plantar aponeurosis strain ${ }^{11}$. And Arch support orthosis can help to stabilize the bone structure and then produce standing stability. Moreover, arch support insole also increases ankle rocker stability. In addition, effective control of foot motion and 
ankle stability may decrease postural sway and the risk of fall in the elderly. The purpose of this study was to evaluate how the different hardness and arch support designs in controlling the posture stability.

\section{METHOD}

Fifteen fall-experienced elderly $(67.67 \pm 2.40 \mathrm{y} / \mathrm{o})$ and eighteen non-faller elderly $(68.67 \pm 3.13$ y/o)were recruited in this study. The elderly were subjected to an exhaustive examination including the collection of demographic data, proprioceptive test, static balance test (double stance, single leg stance, tandem stance), Berg balance scale (BBS), as well as a dynamic balance assessment system tested in eye opened or closed conditions (Biodex Medical System, Inc., USA) with a pressure mat (Xsensor X3, Canada) on top of the platform. The experimental procedure flow chart was shown in Fig 1. Four types of orthotic insoles (named Performace, Proactive, and Hardboot from Footdisc $₫$, and Power step from Dr. Kong) (Fig. 2) . The insole had different arch support hardness used to support ankle stability during ankle rocker motion, and cushions at metatarsal/ heel regions used to protect sensitive foot structure against its strain and proprioception. During each test, foot pressure and the center of pressure (CoP) were recorded and analyzed. Statistical analysis was performance using SPSS v. 17.0 software.

\section{RESULTS \& Discussion}

The demographic data was shown in Table 1, there were no significant for the test subjects. The range of motion and foot function were no difference between two groups except the fall-experienced (faller) had larger forefoot varus (Table 2). In the static balance test, it showed significant high score in single stance and tandem stance test (Table 3). During dynamic balance tests, the faller group showed significant larger maximal CoP excursion particularly in the medial-lateral direction(Fig. 3), as well as the anterior-posterior mean CoP velocity in the condition of eye open (Fig. 4). In the condition of eye closed test, the CoP trajectory increased profoundly, although the faller group was larger than non-fall but was not significant. The increased of M-L sway implies the increase of fall risk, the poor vision condition elevated the falling rate ${ }^{12,13}$. With orthoses, the sway trajectory reduced, among that the Proactive insole (arch height $1.75 \mathrm{~cm}$ ) showed the best posture stability control. It reduced the $\mathrm{M} / \mathrm{L}$ of $\mathrm{CoP}$ excursion with average of $29 \%$ for non-fall and $35 \%$ for faller, respectively (Fig. 5). As a result, we found the elderly with arch support insoles improved $\mathrm{M} / \mathrm{L}$ of CoP excursion and increased postural stability, since the arch support the midfoot bones lock each other to provide foot stability during ankle rocker, and the insole material also promotes the proprioception.

\section{Conclusion}

The assessment of postural control systems in recurrent fallers was essential to design the prevention measures needed to minimize physical consequences of falls in the elderly. The CoP measures during dynamic perturbation were able to explain the variance of postural stability between the faller and nonfaller elderly. Smaller maximal CoP trajectories in $M / L$ direction were found in the non-faller elderly than the faller group. Of the four insoles and barefoot tested, the Footdisc $®$ Proactive insoles ( arch height $1.75 \mathrm{~cm}$ ) had stable longitudinal arch support and heel criddle mechanisms that significantly reduced postural sway. Therefore, for the reasons discussed above, these results indicated the insoles, such as Footdisc $®$ Proactive insoles, had the control capabilities of dynamic postural stability on fall prevention of the elderly.

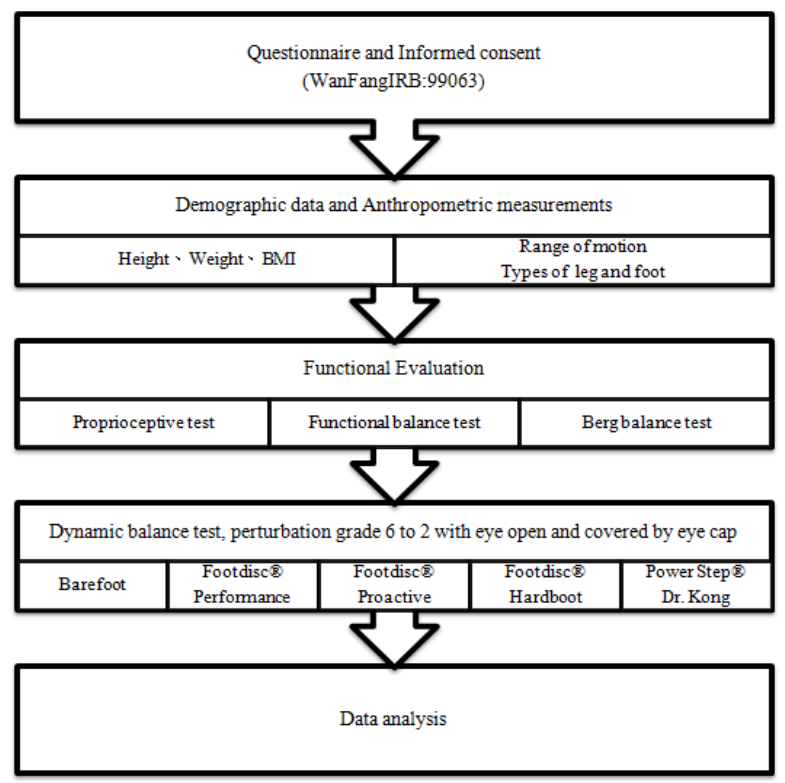

Fig. 1. The experiment flow chart

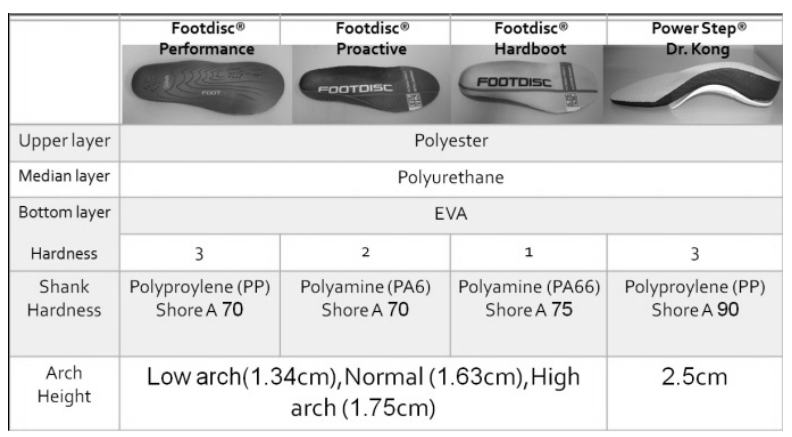

Fig. 2. Tested orthotic insoles 


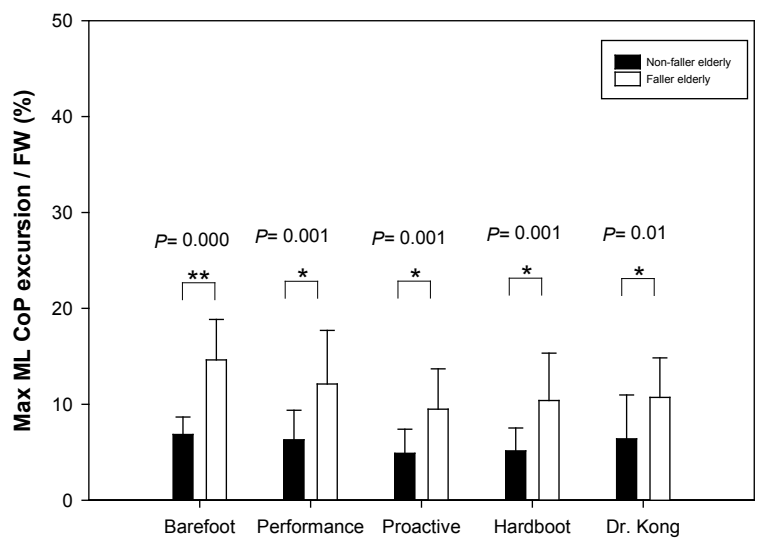

Fig.3. Maximal CoP excursion in the medial-lateral direction between the faller and non-faller elderly in the condition of eye open

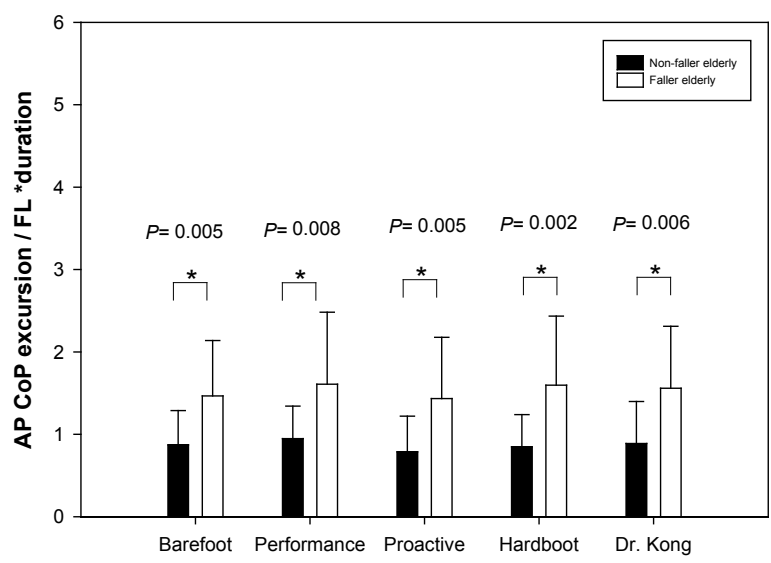

Fig.4. Mean CoP velocity in the anterior-posterior direction between the faller and non-faller elderly in the condition of eye open

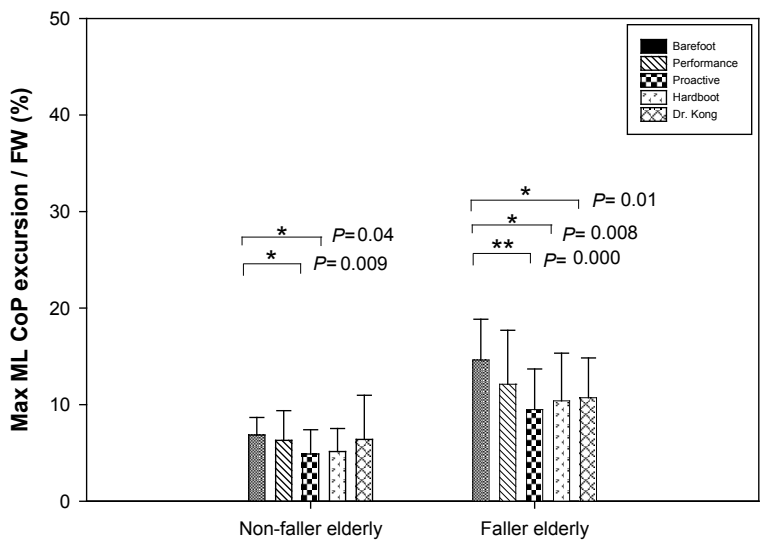

Fig.5. Maximal CoP excursion in the medial-lateral direction with different orthotics between the faller and non-faller elderly in the condition of eye open
Table 1. Demographic data of subjects

\begin{tabular}{lccc}
\hline & $\begin{array}{c}\text { Non-faller } \\
\text { elderly }\end{array}$ & $\begin{array}{c}\text { Faller } \\
\text { elderly }\end{array}$ & P value \\
\hline Subjects & 18 & 15 \\
Age(y/o) & $67.67 \pm$ & $68.87 \pm$ & 0.223 \\
& 2.40 & 3.13 & \\
Body height & $156.03 \pm$ & $156.13 \pm$ & 0.955 \\
(cm) & 4.38 & 6.17 & \\
Body & $56.33 \pm$ & $58.33 \pm$ & 0.459 \\
weight (kg) & 6.99 & 8.39 \\
BMI & $23.17 \pm$ & $24.04 \pm$ & 0.480 \\
& 3.01 & 3.99 & \\
Foot length & $23.34 \pm$ & $23.64 \pm$ & 0.359 \\
(cm) & 0.79 & 1.03 & \\
Foot width & $8.36 \pm 0.72$ & $8.78 \pm 0.97$ & 0.166 \\
(cm) & & & \\
\hline
\end{tabular}

Table 2. Foot function evaluation

\begin{tabular}{lllllll}
\hline & $\begin{array}{c}\text { Non- } \\
\text { faller } \\
\text { elderly }\end{array}$ & $\begin{array}{c}\text { Faller } \\
\text { elderly }\end{array}$ & $\begin{array}{l}\mathbf{P} \\
\text { value }\end{array}$ & $\begin{array}{l}\text { Non- } \\
\text { faller } \\
\text { elder- } \\
\text { ly }\end{array}$ & $\begin{array}{l}\text { Faller } \\
\text { Elder- } \\
\text { ly }\end{array}$ & $\begin{array}{c}\text { P } \\
\text { value }\end{array}$ \\
\hline Dorsiflexion & $22.56 \pm$ & $\begin{array}{l}\text { Left side } \\
22.53 \pm\end{array}$ & 0.989 & $23.44 \pm$ & $\begin{array}{l}\text { Right side } \\
22.67 \pm\end{array}$ & 0.625 \\
& 4.34 & 4.67 & & 4.37 & 4.67 & \\
Plantarflexion & $36.39 \pm$ & $37.93 \pm$ & 0.243 & $36.56 \pm$ & $38.47 \pm$ & 0.169 \\
& 3.96 & 3.39 & & 3.60 & 4.21 & \\
Enversion & $7.61 \pm$ & $8.33 \pm$ & 0.285 & $7.39 \pm$ & $8.20 \pm$ & 0.267 \\
& 1.38 & 2.38 & & 1.29 & 2.74 & \\
Inversion & $15.22 \pm$ & $15.67 \pm$ & 0.580 & $16.27 \pm$ & $15.83 \pm$ & 0.539 \\
& 1.86 & 2.69 & & 2.09 & 1.92 & \\
Tibial Torsion & $9.22 \pm$ & $8.33 \pm$ & 0.348 & $9.50 \pm$ & $8.53 \pm$ & 0.275 \\
(external>0) & 3.06 & 2.09 & & 3.01 & 1.64 & \\
$\begin{array}{l}\text { Forefoot } \\
\text { angle } \\
\text { (valgus }>\mathbf{0} \text { ) }\end{array}$ & $-3.28 \pm$ & $-1.93 \pm$ & 0.069 & $-1.73 \pm$ & $-3.56 \pm$ & $0.018^{*}$ \\
$\begin{array}{l}\text { Rearfoot } \\
\text { angle } \\
\text { (valgus }>\mathbf{0} \text { ) }\end{array}$ & $-1.61 \pm$ & 2.58 & & 2.81 & 1.19 & \\
\hline
\end{tabular}

Table 3. Balance Score from Biodex system

\begin{tabular}{cccc}
\hline & $\begin{array}{l}\text { Non-faller } \\
\text { elderly }\end{array}$ & $\begin{array}{c}\text { Faller } \\
\text { elderly }\end{array}$ & P value \\
\hline BBS & $55.17 \quad \pm$ & $53.93 \pm$ & 0.053 \\
& 1.098 & 2.314 & \\
$\begin{array}{l}\text { (1) Double } \\
\text { stance } \\
\text { (2) Single } \\
\text { left leg } \\
\text { stance }\end{array}$ & $0.64 \pm 0.29$ & $1.36 \pm 0.44$ & 0.275 \\
$\begin{array}{l}\text { (3) Single } \\
\text { right leg } \\
\text { stance }\end{array}$ & $2.29 \pm 0.62$ & $4.54 \pm 1.30$ & $0.015^{*}$ \\
$\begin{array}{l}\text { (4) Tandem } \\
\text { stance (L--R) } \\
\text { (5) Tandem } \\
\text { stance (R--L) }\end{array}$ & $1.58 \pm 0.51$ & $3.29 \pm 0.97$ & $0.026^{*}$ \\
\hline
\end{tabular}




\section{References}

1. Lord, S., Sherrington, C., Menz, H., and Close, J., Falls in Older people: Risk factors and strategies for prevention ( $2^{\text {nd }}$ edition). Cambridge, New York: Cambridge University Press, 2007.

2. Prudham, D., and Evans, J.G., "Factors associated with falls in the elderly: a community study", Age and Ageing, Vol. 10(3), pp.141-146, 1981.

3. O'Connell, B. and Myers, H., "The sensitivity and specificity of the Morse Fall Scale in an acute care setting", Journal of Clinical Nursing, Vol. 11(1), pp. 134-136, 2002.

4. Shumway-Cook, A., and Woollacott, M., Motor Control: Theory and Practical Applications ( ${ }^{\text {nd }}$ edition). Baltimore, MD: Lippincott, Williams and Wilkens, 2000.

5. Amiridis, I.G., Hatzitaki, V., and Arabatzi, F., "Ageinduced modifications of static postural control in humans", Neuroscience Letters, Vol. 350(3), pp.137-140, 2003.

6. Lord, S.R., Ward, J.A., Williams, P., and Anstey, K.J., "An epidemiological study of falls in older community-dwelling women: the Randwick Falls and Fractures Study", Australian Journal of Public Health, Vol. 17(3), pp. 240-245, 2003.

7. Menz, H.B., Morris, M.E., and Lord, S.R., "Foot and ankle characteristics associated with impaired balance and functional ability in older people", Journals of Gerontology - Series A Biological Sciences and Medical Sciences, Vol. 60(12), pp.15461552, 2005.

8. Nitz, J.C., and Choy, N.L. "The efficacy of a specific balance-strategy training programme for preventing falls among older people: A pilot randomized controlled trial", Age and Ageing, Vol. 33(1), pp.52-58, 2004.

9. Menz, H.B., Lord, S.R., and McIntosh, A.S. "Slip resistance of casual footwear : Implications for falls in older adults", Gerontology, Vol. 47(3), pp. 145-149, 2001.

10. Kuhn, D.R., Shibley, A.J., Austin, W.M., and Yochum, T.R., "Radiographic evaluation of weight bearing orthotics and their effect on flexible pes planus", Journal of Manipulative and Physiological Therapeutics, Vol. 22(4), pp. 221-226, 1999.

11. Koglerco, G.F., Solomonidisc, S.E., Paul, J.P. "Biomechanics of longitudinal arch support mechanisms in foot orthoses and their effect on plantar aponeurosis strain", Clinical Biomechanics, Vol. 11(5), pp. 243-252, 1996.

12. Mulford, D., Taggart, H.M., Nivens, A., and Payrie, C., "Arch support use for improving balance and reducing pain in older adult", Applied Nursing Research, Vol. 21(3), pp. 153-158, 2008.

13. Wilson, M.L., Rome, K., Hodgson, D., and Ball, P., "Effect of textured foot orthotics on static and dynamic postural stability in middle-aged females", Gait and Posture, Vol. 27(1) , pp. 36-42, 2008. 